\title{
ENDOMETRIOSE \& EXERCÍCIO: UMA BREVE REVISÃO
}

\author{
Gabriela Teixeira dos Reis da Silva ${ }^{1}$ e Hélder Gabriel Rodrigues da Silva. ${ }^{2}$
}

${ }^{1}$ Graduanda Educação Física - UNISINOS -RS.

2Pós-graduando Ciências do Exercício - ULBRA/Canoas - RS.

Acesso DOI: http://dx.doi.org/10.34059/ciejop.2019v28i1-10

A endometriose é uma condição ginecológica comum e complexa, é um distúrbio estrogênio-dependente caracterizado por tecido endometrial em sítios extrauterinos. Seus sintomas incluem dor pélvica crônica (DPC), dismenorreia, dispareunia, disquezia, disúria e infertilidade. Os tratamentos que visam diminuir a circulação das concentrações de estradiol. Tanto os exames quanto o tratamento, juntamente com consultas e procedimentos cirúrgicos, estudos mostram que o impacto econômico da endometriose é considerável. As pacientes com endometriose exibem redução na qualidade de vida (QV). Para manutenção da QV e tratamento auxiliar da endometriose é utilizado o exercício físico, que por sua essência pode contribuir em diferentes aspectos. Sendo assim, o objetivo deste estudo foi analisar os efeitos do exercício em mulheres com endometriose, além de sua interação com tratamentos e qualidade de vida. A pesquisa foi realizada nas bases de dados PubMed e Scholar Google. Foram utilizados os DeCS: "endometriosis", "exercise", "treatment" e "quality of life". Os artigos foram analisados manualmente por dois revisores, de forma independente. Após a seleção feita por critérios de inclusão e exclusão, foi selecionado 29 artigos procedeu-se a leitura integral dos documentos. Os estudos que avaliaram QV em pacientes com endometriose exibiram baixa significativa dos domínios físicos e psicológicos. Os fatores que contribuíram para melhora da QV foi a prática de exercícios físicos, seguido pelo fator "maior renda", este sendo um fator pouco modificável. Outros estudos avaliaram DPC e QV através de exercícios de relaxamento e técnicas de postura associadas à respiração comparado à um grupo controle. A técnica demonstrou eficácia no alivio da DPC e melhora da QV. O exercício é uma das estratégias mais eficazes para aumentar os níveis de serotonina, podendo estimular a produção de substâncias químicas que elevam o humor, assim podendo diminuir aspectos antidepressivos e melhorando a QV, principalmente nos aspectos físicos e psicológicos.

Palavras-chave: endometriose, exercício, qualidade de vida. 